\title{
Review
}

\section{Glucosinolate metabolism, functionality and breeding for the improvement of Brassicaceae vegetables}

\author{
Masahiko Ishida*1), Masakazu Hara $^{2)}$, Nobuko Fukino ${ }^{3)}$, Tomohiro Kakizaki ${ }^{3)}$ and Yasujiro Morimitsu ${ }^{4)}$ \\ 1) NARO Institute of Vegetable and Tea Science, Tsukuba Vegetable Research Station, 3-1-1 Kannondai, Tsukuba, Ibaraki 305-8666, Japan \\ 2) Research Institute of Green Science and Technology, Shizuoka University, 836 Ohya, Shizuoka 422-8529, Japan \\ 3) NARO Institute of Vegetable and Tea Science, 360 Kusawa, Ano, Tsu, Mie 514-2392, Japan \\ 4) The Department of Food and Nutritional Sciences, The Graduate School of Humanities and Sciences, Ochanomizu University, 2-1-1 \\ Otsuka, Bunkyo, Tokyo 112-8610, Japan
}

Unique secondary metabolites, glucosinolates ( $S$-glucopyranosyl thiohydroximates), are naturally occurring S-linked glucosides found mainly in Brassicaceae plants. They are enzymatically hydrolyzed to produce sulfate ions, D-glucose, and characteristic degradation products such as isothiocyanates. The functions of glucosinolates in the plants remain unclear, but isothiocyanates possessing a pungent or irritating taste and odor might be associated with plant defense from microbes. Isothiocyanates have been studied extensively in experimental in vitro and in vivo carcinogenesis models for their cancer chemopreventive properties. The beneficial isothiocyanates, glucosinolates that are functional for supporting human health, have received attention from many scientists studying plant breeding, plant physiology, plant genetics, and food functionality. This review presents a summary of recent topics related with glucosinolates in the Brassica family, along with a summary of the chemicals, metabolism, and genes of glucosinolates in Brassicaceae. The bioavailabilities of isothiocyanates from certain functional glucosinolates and the importance of breeding will be described with emphasis on glucosinolates.

Key Words: glucosinolate, isothiocyanate, biosynthesis, gene, health, Brassica, plant breeding.

\section{Introduction}

The Brassicaceae family, also called Cruciferae, includes around 375 genera and about 3,200 species (LeCoz and Ducombs 2006), including many economically important plants such as leaf and root vegetables, oilseed and condiment crops, and the model plant Arabidopsis thaliana. Brassicaceae vegetables are widely cultivated, with many genera, species, and cultivars including Brassica rapa (Chinese cabbage, Chinese mustard, bok choy and turnip), B. oleracea (cabbage, broccoli, cauliflower, kale, Brussels sprouts and kohlrabi), B. napus (rapeseed and rutabaga), B. juncea (mustard green), and Raphanus sativus (radish).

Glucosinolates, secondary metabolites found in Brassicaceae and related families, have three moieties: a $\beta$ thioglucose moiety, a sulfonated oxime moiety, and a variable aglycone side chain derived from a $\alpha$-amino acid. Glucosinolates, of which nearly 200 types having different substituents have been identified, are classifiable into three

Communicated by T. Nishio

Received September 20, 2013. Accepted February 24, 2014.

*Corresponding author (e-mail: ishimame@affrc.go.jp) classes based on the structure of different amino acid precursors: aliphatic glucosinolates, indole glucosinolates, and aromatic glucosinolates (Fig. 1). Table 1 shows the glucosinolates found in Brassicaceae vegetables. Glucosinolates of each group are synthesized through a metabolic pathway that is independent and which shares a common set of enzymes involved in the core structure formation of glucosinolates under genetic control (Fahey et al. 2001, Halkier and Gershenzon 2006, Hirani et al. 2012, Kim et al. 2002, Mithen et al. 2000). The composition and contents of glucosinolates are influenced by the genotype, climate and cultivation conditions including fertilization, harvest time and plant position (Rangkadilok et al. 2002, Sang et al. 1984, Tripathi and Mishra 2007, Verkerk et al. 2009). They differ completely among plant genera and among different organs (Rosa et al. 1997).

When plant tissue damage occurs because of disruption, glucosinolates are hydrolyzed quickly with inherent myrosinase ( $\beta$-thioglucoside glucohydrolase, thioglucosidase, EC3.2.1.147), resulting in production of isothiocyanates, thiocyanates, nitriles, goitrin and epithionitriles, depending upon $\mathrm{pH}$ and other conditions (Fig. 2) (Bones and Rossiter 1996, 2006, Fenwick et al. 1983). The system in which 


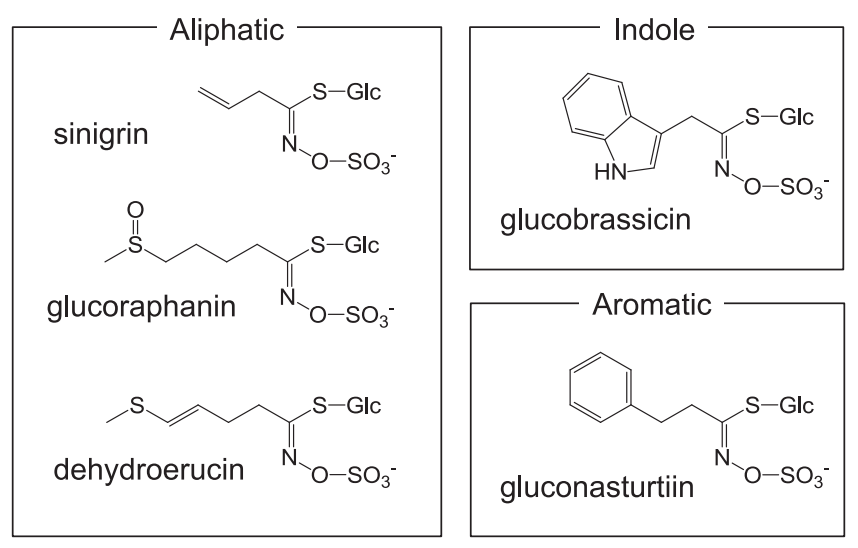

Fig. 1. Examples of glucosinolates found in Brassicaceae vegetables.

Table 1. Common and chemical name of major glucosinolates present in Brassicaceae vegetables

\begin{tabular}{ll}
\hline \hline Common name & Chemical name (side chain R) \\
\hline $\begin{array}{c}\text { Aliphatic glucosinolate } \\
3 \text { carbon chain length } \\
\text { Glucoiberverin }\end{array}$ & \\
Glucoiberin & 3-Methylthiopropyl \\
Sinigrin & 3-Methylsulfinylpropyl \\
4 carbon chain length & 2-Propenyl \\
Glucoerucin & \\
Dehydroerucin & 4-Methylthiobutyl \\
Glucoraphanin & 4-Methylthio-3-butenyl \\
Glucoraphenin & 4-Methylsulfinylbutyl \\
Gluconapin & 4-Methylsulfinyl-3-butenyl \\
Progoitrin & 3-Butenyl \\
5 carbon chain length & 2-Hydroxy-3-butenyl \\
Glucoberteroin & \\
Glucoalyssin & 5-Methylthiopentyl \\
Glucobrassicanapin & 5-Methylsulfinylpentyl \\
Gluconapoleiferin & 4-Pentenyl \\
Aromatic glucosinolate & 2-Hydroxy-4-pentenyl \\
Gluconasturtiin & \\
Indole glucosinolate & 2-Phenylethyl \\
Glucobrassicin & \\
4-Hydroxyglucobrassicin & 3-lndolyl methyl \\
4-Methoxyglucobrassicin & 4-Hydroxy-3-indolymethyl \\
Neoglucobrassicin & 4-Methoxy-3-indolylmethyl \\
& N-methoxy-3-indolymethyl \\
\hline
\end{tabular}

glucosinolate and myrosinase come into contact in cases of tissue destruction is called "the glucosinolate-myrosinase system" (Bones and Rossiter, 1996, 2006, Rask et al. 2000). Isothiocyanates are important pungent compounds that affect the taste and odor of Brassicaceae plants (Fahey et al. 2001, Mithen et al. 2000, Williams and Pun 2011). However, the consumption of Brassicaceae vegetables containing glucosinolates might reduce the risk of carcinogenesis and particular disease in humans (Traka and Mithen 2009). Therefore, glucosinolate, an isothiocyanate precursor, has also been in the spotlight.

Along with the acute progression of aging and the increase of lifestyle diseases in economically developed countries, maintaining and enhancing good health through dietary habits has become a crucially important social issue. For this purpose, phytochemicals in dietary vegetables are

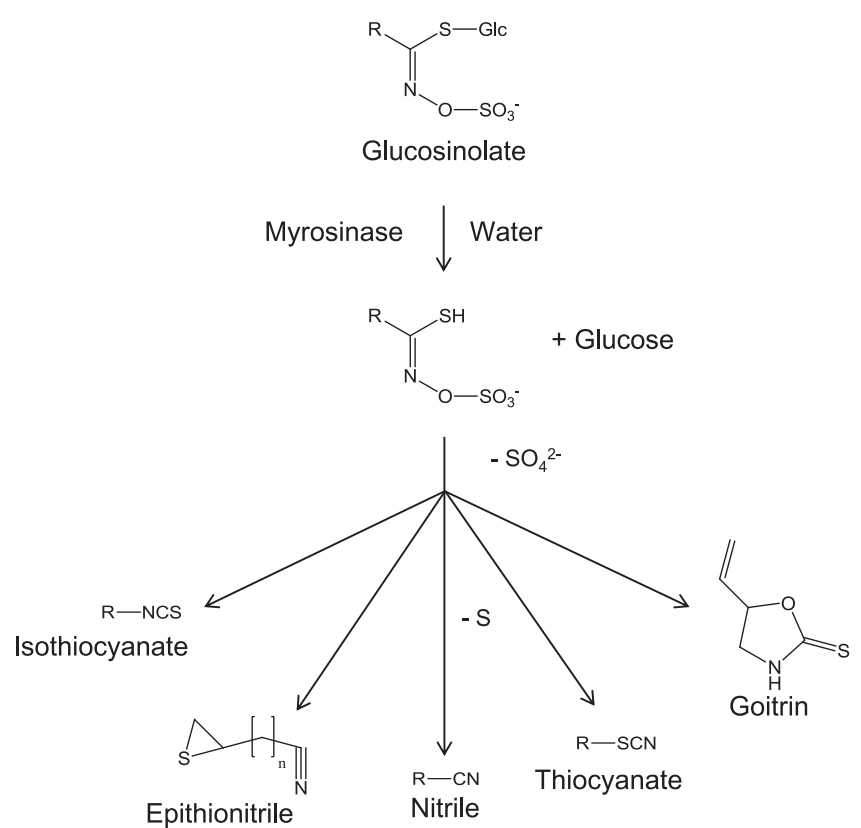

Fig. 2. Isothiocyanate, epithionitrile, nitrile, thiocyanate, and goitrin generated from glucosinolate.

noteworthy. Among the many varieties of vegetables, Brassicaceae vegetables have received the most attention because their unique constituents, glucosinolates, are abundant in edible parts and are regarded as most likely to maintain human health through continuous consumption. For the future, the breeding of Brassicaceae vegetables by particularly addressing beneficial glucosinolates is expected to grow in importance. The purpose of this review was to collect research findings related to recent developments in glucosinolates and their breakdown products for the breeding of Brassicaceae vegetables.

\section{Structure, metabolism, and biosynthetic genes of glucosinolates in Brassicaceae vegetables}

\section{Glucosinolate biosynthesis}

The biosynthetic pathway of glucosinolates has been almost entirely elucidated mainly by Arabidopsis. Many reviews have presented summaries of the results (such as Grubb and Abel 2006, Halkier and Gershenzon 2006, Sønderby et al. 2010b). Glucosinolates are biosynthesized from amino acids. The three glucosinolate subtypes have their corresponding precursors. Aliphatic glucosinolates are derived from alanine, leucine, isoleucine, valine, and methionine. Indole glucosinolates and aromatic glucosinolates are derived respectively from tryptophan and phenylalanine or tyrosine. The glucosinolate biosynthetic pathways comprise three independent steps: the chain elongation stage, formation of a core glucosinolate structure, and secondary modification (Fig. 3).

Aliphatic glucosinolates have various side chains with different lengths determined by the chain elongation steps. 


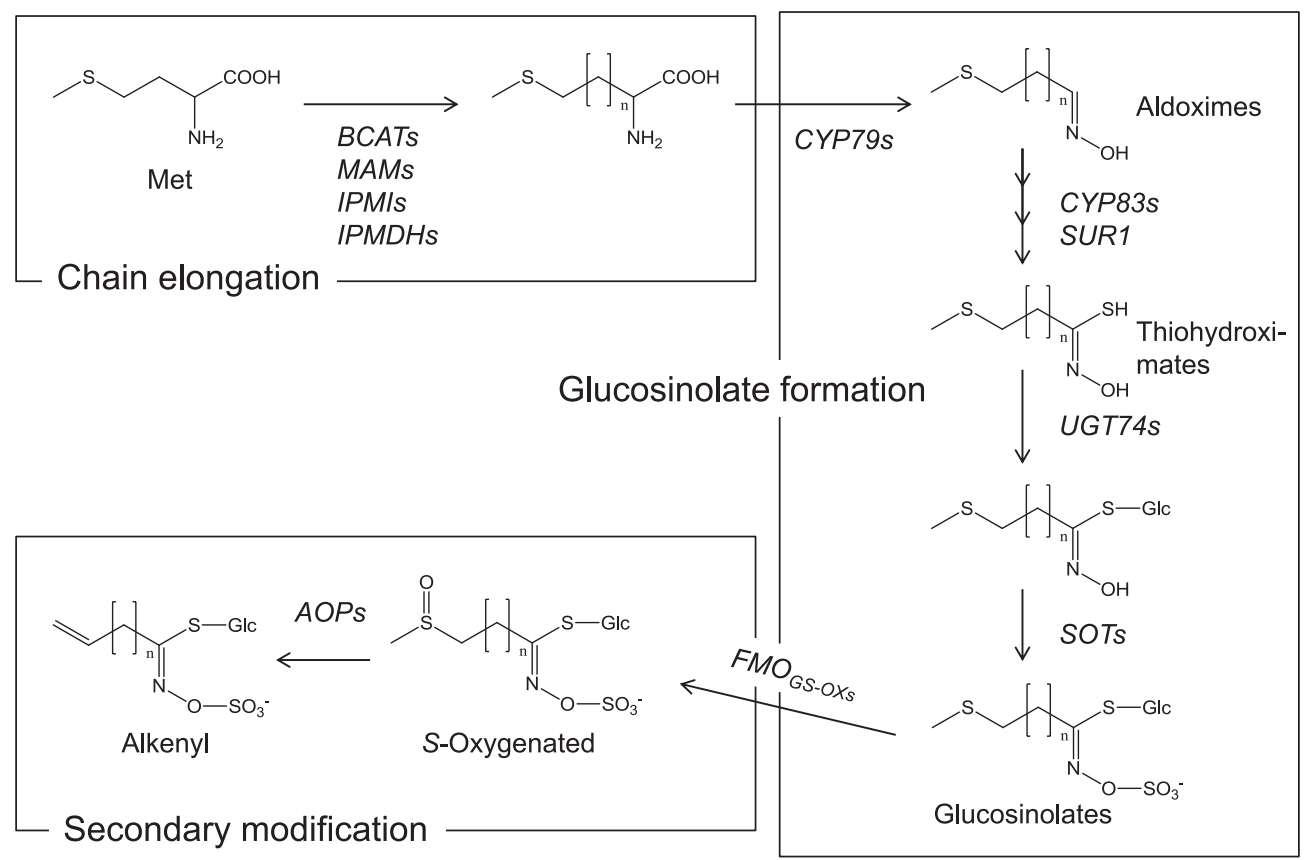

Fig. 3. Schematic pathway of aliphatic glucosinolate biosynthesis. The pathway consists of chain elongation, glucosinoate formation, and secondary modification. Details can be found in the review articles presented in the text.

The first process of chain elongation is the deamination of amino acids such as methionine to the corresponding 2-oxo acids by a branched-chain amino acid aminotransferase (BCAT). The 2-oxo acids are precursors of the elongation reaction by a methylene group. The elongation proceeds by methylthioalkylmalate synthase (MAM), isopropylmalate isomerase (IPMI), and isopropylmalate dehydrogenase (IPMDH). Finally, the elongated 2-oxo acids are transformed to the corresponding amino acids by BCAT. This chain elongation also takes place in the biosynthesis of aromatic glucosinolates, but does not occur in the formation of indole glucosinolates.

Amino acids, including elongated ones, then undergo following step: the formation of core glucosinolate structure. Cytochromes P450 (CYP79s) convert the amino acids to aldoximes, which are then oxidized to the activated forms by CYP83s. The activated forms are transformed to thiohydroximates via glutathione conjugation and the $C$-S lyase (SUR1) reaction. The thiohydroximates are finally converted to the glucosinolate structure by the $S$-glucosyltransferases of the UGT74 family and the sulfotransferases SOTs. After the glucosinolate structure formation, the side chains are modified by oxygenation, hydroxylation, alkenylation, benzoylation, and methoxylation. The $S$-oxygenation of aliphatic glucosinolates is a common modification conducted by

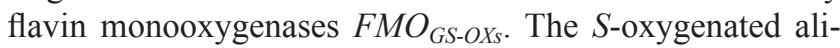
phatic glucosinolates, such as glucoraphanin, are found in many Brassicaceae vegetables. Alkenyl glucosinolates such as sinigrin are produced by 2-oxoglutarate-dependent dioxygenases $A O P S$ from $S$-oxygenated glucosinolates. Glucobrassicin, which is a common indole glucosinolate, is hydroxylated by CYP81F2 in Arabidopsis. Methoxylations might occur by unidentified $O$-methyltransferases. The level and profile of glucosinolates are determined respectively in Arabidopsis by transcription factors such as MYB28, MYB29, and MYB76 for aliphatic glucosinolates and by MYB34, MYB51, and MYB122 for indole glucosinolates (Sønderby et al. 2010a).

Biosynthetic genes and transcription factors related to glucosinolates have been identified using Arabidopsis. The backbone of biosynthesis found in Arabidopsis is expected to be the same as those in Brassicaceae vegetables. The association between the glucosinolate biosynthetic genes of Arabidopsis and those found in Brassicaceae vegetables is described below.

\section{Glucosinolate-myrosinase system}

Glucosinolates are hydrolyzed by thioglucosidases called myrosinases to isothiocyanates, thiocyanates, nitriles, epithionitriles etc., which are bioactive compounds (Fig. 2) (Kissen et al. 2009). Presumably, glucosinolates are hydrolyzed only slightly under intact conditions, in which myrosinases are separated from the location of glucosinolates (Husebye et al. 2002, Kelly et al. 1998, Koroleva et al. 2000). Once tissues are mechanically damaged, however, glucosinolates are hydrolyzed intensively by myrosinases. This hydrolyzing reaction is called the glucosinolatemyrosinase system (Bones and Rossiter 1996, 2006, Rask et al. 2000). Although isothiocyanates are main products from the myrosinase reaction, nitriles/epithionitriles and thiocyanates can be generated respectively by the associations of an epithiospecifier protein and a thiocyanate-forming protein (Bones and Rossiter 2006). The epithiospecifier protein determines the composition of hydrolysis products in each 
Brassicaceae crop. Unlike Brassica species, no epithiospecifier protein is detected in Sinapis alba or R. sativus, which produce few nitriles/epithionitriles (Foo et al. 2000). A glucosinolate, progoitrin, is hydrolyzed by myrosinases to form a cyclic thiocarbamate goitrin which is an antinutritional compound that reduces the production of thyroid hormones (Stoewsand 1995). Hydrolysis products of glucosinolates are related to pigment formation. Carboline compounds derived from 4-methylthio-3-butenyl isothiocyanate, which is a hydrolyzation compound of dehydroerucin, are necessary factors for the formation of yellow pigments in salted radish roots (Ozawa et al. 1990). Moreover, this glucosinolatemyrosinase system has been described as related to plantinsect and plant-pathogen interactions. Several studies have implicated glucosinolate degradation products in plant defense against insects, pathogens, and herbivores (Agrawal and Kurashige 2003, Hopkins et al. 2009, Manici et al. 1997, Rask et al. 2000, Tierens et al. 2001).

Myrosinases are localized in myrosin cells, which are protein-rich idioblasts found mainly in the tissues of imbibed seeds. However, such myrosin cells have been observed in Brassicaceae crop vegetative organs. Myrosinase was localized in the epidermis and the vascular cambium of the radish and turnip taproots and the Japanese horseradish (wasabi) rhizome (Hara et al. 2000, 2001). This distribution of myrosinases, called a "double castle wall structure" is likely to be common among Brassicaceae vegetables. In the flower stalk of Arabidopsis, myrosinases are expressed both in the phloem cells and the guard cells, but glucosinolates accumulate in the S-cells which are adjacent to the phloem cells. In fact, spatial separation of myrosinases from glucosinolates is the basis of the glucosinolate-myrosinase system.

Nutritional and environmental factors regulating glucosinolate production

The accumulation of aliphatic glucosinolates in B. rapa is enhanced by low nitrogen and high sulfur supplies (Chen et al. 2006). Glucose promoted aliphatic glucosinolate biosynthesis in Arabidopsis (Miao et al. 2013). The glucosinolate levels in B. napus were elevated by wounding, methyl jasmonate, and fungal infection (Brader et al. 2001). Some intriguing results have been obtained for the relation between high-temperature stress and glucosinolate synthesis. Exposure of Brassicaceae vegetables to high temperatures is known to enhance the higher aliphatic glucosinolate contents (Charron and Sams 2004, Pereira et al. 2002). A glucosinolate-deficient mutant of Arabidopsis showed thermosensitivity and less heat shock protein (HSP) 90 expression after high-temperature stress (Ludwig-Müller et al. 2000). Moreover, exogenous application of isothiocyanates to Arabidopsis enhanced its thermotolerance and induced the expression of HSP genes (Hara et al. 2013). These results suggest that isothiocyanate is a signaling molecule that promotes thermotolerance in plants.

\section{Bioavailability and functionality of isothiocyanates derived from glucosinolates of Brassicaceae vegetables}

\section{Isothiocyanates against human pathogens}

Brassicaceae vegetables have been used by human beings not only as food materials but also for their medicinal properties. The well-known bioactivities of Brassicaceae vegetables have been investigated for antibacterial and antifungal activities of isothiocyanates (Kojima and Ogawa 1971, Uda et al. 1993) from ancient times in human history. Glucosinolates and their breakdown products, isothiocyanates, have also been used for their fungicidal, bactericidal and nematocidal properties, which are readily linked to plant defenses. Not only the plant, but also the antimicrobial activities of isothiocyanates such as allyl isothiocyanate in mustard or Japanese horseradish (wasabi) against various human pathogens have been worth using for their medicinal effects. Even in recent research, sulforaphane (4-methylsulfinylbutyl isothiocyanate), a distinguished isothiocyanate in broccoli and broccoli sprouts, has shown an inhibitory effect for urease from Helicobacter pylori (Fahey et al. 2013).

Promise of cancer chemopreventive agents by inducing phase 2 enzymes

The development of natural anticancer constituents from edible plants is extremely important for the inclusion of potential cancer chemopreventive agents in dairy foods. Epidemiological reports have described that Brassicaceae vegetables lower the risk of many cancers (Herr and Büchler 2010). Glutathione $S$-transferase (GST) is a family of detoxification enzymes (phase 2 enzymes) consisting of class $\alpha$, $\mu, \pi$, and $\theta$ isoforms. Induction of phase 2 enzymes such as GST and NADP(H) quinone oxidoreductase 1 (NQO1) have been studied in Brassicaceae vegetables such as broccoli sprouts (Kostova et al. 2007, Munday et al. 2008, Zhang et al. 2006), cabbage (Whitty and Bjeldanes 1987), and Japanese horseradish (Morimitsu et al. 2000, 2002). Results demonstrated that many isothiocyanates derived from Brassicaceae vegetables and certain fruits (papaya and so on) show phase 2 induction in cultured cells and rodents. Sulforaphane was identified initially as a potential inducer of NQO1 in Hepa lclc7 cell culture (Zhang et al. 1992). To date, sulforaphane has been proved in other mechanisms of chemopreventive activities such as cell cycle arrest and apoptosis induction (Gamet-Payrastre et al. 2000, Parnaud et al. 2004).

\section{Phase 2 induction mechanisms of isothiocyanates sensing by Keap1}

Although isothiocyanates are widely known as effective phase 2 inducers, phase 2 enzymes are also induced by phenols (Piero et al. 2006), organosulfurs (Wu et al. 2002), and indoles (van Lieshout et al. 1998). Many detoxification enzymes including GST are regulated through the antioxidant response element (ARE), a gene control region (Fig. 4). Actually, ARE is regulated by two proteins: nuclear respiratory 


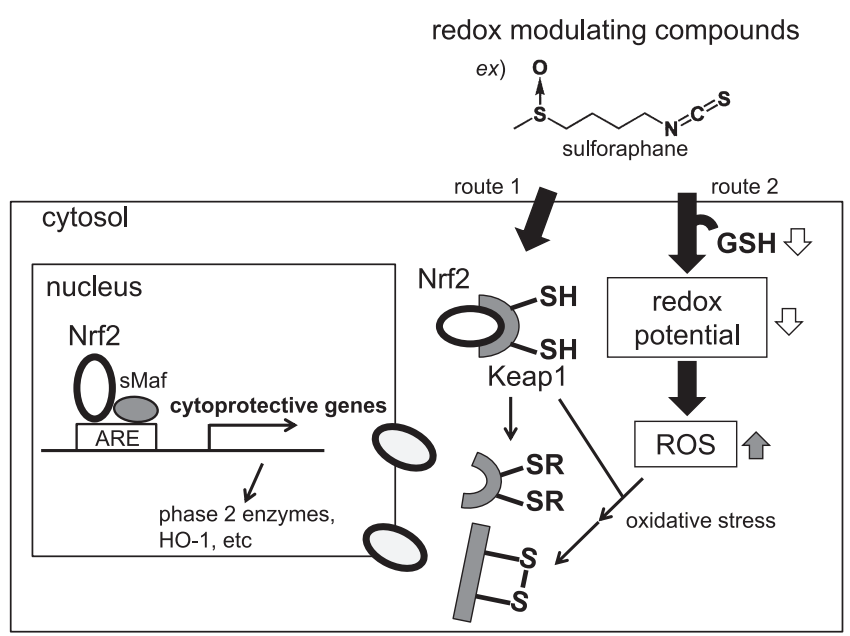

Fig. 4. Reliable scheme for isothiocyanates (redox inducers) activates the Keap1/Nrf2/ARE pathway. When oxidoreductive compounds such as isothiocyanates in Brassicaceae vegetables are absorbed into the cell, the highly reactive cysteine residues of sensor protein Keap1 are modified. Conformational changes of Keap1 repress Nrf2, which subsequently undergoes nuclear translocation. In heterodimeric combination with small Maf transcription factors, it binds to ARE and recruits the basal transcriptional machinery to activate transcription of cytoprotective genes.

factor 2 (Nrf2) and Kelch-like ECH-associated protein 1 (Keap1). Keap1 is an inhibitor of Nrf2, which is a transcriptional activator of ARE. If inducers such as sulforaphane disrupt the Keap1-Nrf2 complex by reacting with thiol residues in Keap1 (route 1 in Fig. 4), or by reacting with glutathione (GSH), which cause the formation of reactive oxygen species (ROS) in the cytosol of cells (route 2 in Fig. 4), then Nrf2 migrates to the nucleus where it forms heterodimers with other transcription factors such as small Maf binding to ARE, and accelerates the transcriptional activity. Many studies have clarified phase 2 induction mechanisms by redox-modulating compounds such as isothiocyanates (Dinkova et al. 2002, Watai et al. 2007).

Necessary structures of isothiocyanates for potent phase 2 inducers and other functions

The chemical moiety of isothiocyanate $(-\mathrm{N}=\mathrm{C}=\mathrm{S})$ is a reactive function with electrophiles such as glutathione and other sulfhydryl-containing molecules (RSH) in the cells. Therefore, the isothiocyanate moiety has been proved to be necessary for the induction of phase 2 enzymes (Morimitsu et al. 2002). Additionally, a potent antimicrobial effect must exist for the isothiocyanate moiety among related compounds. Regarding the kinds of alk(en)yl sidechains of isothiocyanates, $\omega$-methylthioalk(en)yl or $\omega$ methylsulfinylalk(en)yl moieties were preferred rather than normal alk(en)nyl ones. The length of the alk(en)nyl side chain is affected by the hydrophobicities of isothiocyanates. Fewer than 10 carbons (10C) would be better (Morimitsu et al. 2002). Considering sulforaphane in broccoli, it has the $\omega$-methylsulfinylbutyl moiety and four-carbon (4C) chain length between both ends. Based on these results, the chemical structures of isothicyanates are extremely important for their functionality. Therefore, the accumulation of beneficial glucosinolates such as glucoraphanin (the precursor glucosinolate of sulforaphane) in edible parts is expected to be a good strategy for improving Brassicaceae vegetables using breeding techniques as described hereinafter.

\section{Breeding emphasizing glucosinolates}

\section{Glucosinolate analysis}

To date, numerous methods have been developed for the optimized extraction, and analysis of individual and total glucosinolates according to the need for quantitative or qualitative information, analytical speed, analytical accuracy, or combinations of these factors. Depending on the purpose, determining a suitable pretreatment method and analytical method is important. Detailed information for these analyses was presented in earlier reviews (Clarke 2010, Fahey et al. 2001, Griffiths et al. 1998, Kiddle et al. 2001, Mithen et al. 2000).

Prevention of myrosinase activity is necessary during the glucosinolate extraction procedure in vegetative tissue. For this reason, several extraction methods have been used specifically to prevent activation of myrosinase. Generally, extractions are conducted at temperatures of $65-100^{\circ} \mathrm{C}$, close to the water solvent or $70 \%$ aqueous methanol boiling point. The most widely used extraction method is that of The International Organization for Standardization (1992), which uses a sample that has been powdered after freeze-drying. Myrosinase can also be deactivated in wet tissues by a microwaving treatment. In radish, a method has also been used by which a sample is cut into $1-3 \mathrm{~cm}$ fragments from leaf, stem, root, etc., chilled below $5^{\circ} \mathrm{C}$ and extracted with 70-80\% hot methanol (Carlson et al. 1985, Ishii et al. 1989). However, these processes were restricted to extraction of a few samples because of time-consuming sample preparation. Moreover, hot methanol vapor is poisonous and flammable, presenting dangers of high-temperature conditions. Ishida et al. (2011) previously reported a simple method for the extraction of glucosinolates from lyophilized radish roots using methanol at room temperature without hot methanol or hot water. This method provides rapid extraction of glucosinolates from radish roots. It is expected that this is applied to other Brassicaceae vegetables.

A well-known analytical method used for glucosinolates is desulfonation of glucosinolates with sulfatase with subsequent analysis using a reversed phase high-performance liquid chromatography (HPLC) gradient system (Bjerg and Sørensen 1987, Bjorkqvist and Hase 1988). An ion-pair method has also been developed, by which extracted glucosinolates are analyzed directly using HPLC with a reversephase column using an ion-pair reagent without desulfation (Mellon et al. 2002, Rangkadilok et al. 2002). These methods provide reliable quantitative data and information related to glucosinolate variation, but they require much time 
and labor for analyses and for special equipment. Therefore, a simple method for quantitative analysis of glucosinolates is necessary for the fields of plant breeding and food processing. For the Japanese common or pungent radish, extremely high percentages of dehydroerucin were confirmed in the roots. For this reason, Ishida et al. (2012a), by modification of the method of Thies (1982), developed a palladium colorimetric method that can be used simply and rapidly for the estimation of total glucosinolate contents. The colorimetric method does not provide quantitative or qualitative information related to individual glucosinolates, but it extremely useful for analyzing the total glucosinolate contents of Japanese radish cultivars and breeding lines developed from a cross between Japanese radish cultivars.

\section{Glucosinolate profiles in Brassicaceae vegetables}

Glucosinolate contents of Brassicaceae are influenced by environmental factors such as soil, climate and cultivation conditions including fertilization, harvest time, and plant position. However, wide genetic variations in the contents and composition of glucosinolates have been reported from previous studies (Carlson et al. 1987, Ishida et al. 2012a, Padilla et al. 2007, Rosa et al. 1997, Verkerk et al. 2009, Yang and Quiros 2010). In general, there is greater diversity exists in both the amount and profile of glucosinolate in $B$. oleracea as opposed to B. rapa. In $R$. sativus, the genetic diversity of the glucosinolate profile is extremely narrow. Similarly, each vegetable species contains many major and minor glucosinolates (Fahey et al. 2001). The Brassicaceae vegetable tissues include one or more major aliphatic glucosinolates. Table 2 shows aliphatic glucosinolate profiles of main Brassicaceae vegetables. Generally, Brassicaceae vegetables include an alkyl side chain with 3-5 carbons. Glucoiberin is contained in cabbage, broccoli, and cauliflower in $B$. oleracea. Sinigrin is produced in $B$. oleracea vegetables, mustard green (B. juncea). Glucoerucin is included mainly in garden rocket (Eruca sativa). Glucoraphanin, a functional component, is found in B. oleracea such as broccoli, cauliflower, and kohlrabi. Gluconapin and progoitrin are included in many Brassica vegetables such as B. rapa (Chinese cabbage, mustard spinach, mizuna, and turnip), $B$. oleracea (cabbage, broccoli and cauliflower), B. juncea (mustard green), and B. napus (rapeseed vegetable). Dehydroerucin, which is specific to radish ( $R$. sativus), is the dominant aliphatic glucosinolate, accounting for over $80 \%$ of the all glucosinolates. Glucobrassicanapin is the main glucosinolate constituent of $B$. rapa vegetables.

In Brassica species, diversity based on glucosinolates composition is related to $\mathrm{A}, \mathrm{B}$ and $\mathrm{C}$ genomes. With regard to the three ancestral Brassica species with diploid genome chromosomes: B. nigra (BB, $2 n=16)$ contains glucosinolates with three carbon $(C)$ side chains, derived from a single elongation reaction: $B$. oleracea $(\mathrm{CC}, 2 n=18)$ contains glucosinolates with either $3 \mathrm{C}$ or $4 \mathrm{C}$ side chains; and $B$. rapa (AA, $2 n=20$ ) contains glucosinolates with either $4 \mathrm{C}$ or $5 \mathrm{C}$ side chains. Three amphidiploid Brassica species, B. juncea (AABB, $2 n=36)$, B. napus (AACC, $2 n=38$ ), and $B$. carinata $(\mathrm{BBCC}, 2 n=34)$, possess glucosinolate

Table 2. Distribution of aliphatic glucosinolates among main Brassicaceae vegetables (Cartea and Velasco 2008)

\begin{tabular}{|c|c|c|c|c|c|c|c|c|c|c|c|c|}
\hline \multirow{2}{*}{$\begin{array}{l}\text { Botanical } \\
\text { classification }\end{array}$} & \multicolumn{3}{|c|}{3 carbon side chains } & \multicolumn{6}{|c|}{4 carbon side chains } & \multicolumn{3}{|c|}{5 carbon side chains } \\
\hline & $\begin{array}{l}\text { Gluco- } \\
\text { iberverin }\end{array}$ & $\begin{array}{l}\text { Gluco- } \\
\text { iberin }\end{array}$ & Sinigrin & $\begin{array}{l}\text { Gluco- } \\
\text { erucin }\end{array}$ & $\begin{array}{c}\text { Dehydro- } \\
\text { erucin }\end{array}$ & $\begin{array}{l}\text { Gluco- } \\
\text { raphanin }\end{array}$ & $\begin{array}{l}\text { Gluco- } \\
\text { raphenin }\end{array}$ & $\begin{array}{c}\text { Gluco- } \\
\text { napin }\end{array}$ & Progoitrin & $\begin{array}{l}\text { Gluco- } \\
\text { alyssin }\end{array}$ & $\begin{array}{c}\text { Glucobrassi- } \\
\text { canapin }\end{array}$ & $\begin{array}{c}\text { Gluco- } \\
\text { napoleiferin }\end{array}$ \\
\hline \multicolumn{13}{|l|}{ Brassica rapa } \\
\hline Chinese cabbage & & + & & & & & & $*$ & + & & $*$ & + \\
\hline bok choy ${ }^{a}$ & & & & & & & & $*$ & $*$ & & + & + \\
\hline turnip & & + & & + & & & & $*$ & $*$ & & $*$ & + \\
\hline turnip greens & + & + & & + & & + & & $*$ & + & + & $*$ & + \\
\hline Brassica nigrab $^{b}$ & & & $*$ & & & & & & & & & \\
\hline \multicolumn{13}{|l|}{ Brassica oleracea } \\
\hline white cabbage & + & $*$ & $*$ & + & & + & & + & + & + & + & \\
\hline red cabbage & + & $*$ & $*$ & & & + & & + & + & & & \\
\hline broccoli & & + & + & + & & $*$ & & $*$ & $*$ & + & + & + \\
\hline cauliflower & + & $*$ & $*$ & & & + & & & $*$ & & & \\
\hline kale & + & $*$ & $*$ & & & + & & + & + & & & \\
\hline Brussels sprouts & + & + & $*$ & & & + & & + & $*$ & & & \\
\hline kohlrabi & + & + & $*$ & & & + & & + & + & + & & \\
\hline Brassica juncea $^{b}$ & & & $*$ & & & & & + & & & + & + \\
\hline \multicolumn{13}{|l|}{ Brassica napus } \\
\hline rapeseed & & & & & & + & & & + & & + & + \\
\hline swede & + & & & & & & & + & + & + & $*$ & + \\
\hline Brassica carinata $^{b}$ & & & $*$ & & & & & & & & & \\
\hline \multicolumn{13}{|l|}{ Raphanus sativus } \\
\hline $\operatorname{radish}^{c}$ & & & & & $*$ & & + & & & & & \\
\hline \multicolumn{13}{|l|}{ Eruca sativa } \\
\hline garden rocket $^{d}$ & & & & $*$ & & $*$ & & & & & & \\
\hline
\end{tabular}

Major aliphatic glucosinolates found in each crop are shown in $*$ symbol.

Data sources: ${ }^{a}$ Wiesner et al. (2013), ${ }^{b}$ Kirkegaard and Sarwar (1998), ${ }^{c}$ Ishida et al. (2012a), ${ }^{d}$ Kim and Ishii (2007). 
composition that consists of the profiles of two elementary species. As with elongation, modifications of side chains in Brassica are also more limited than those found throughout the entire family.

Genetic system controlling glucosinolate biosynthesis in Brassicaceae vegetables

Glucosinolate contents have quantitative inheritance, which is regulated by complex genetic factors and which is affected by environmental factors (Hirani et al. 2012). As described in the "Glucosinolate biosynthesis" section above, most genes involved in the glucosinolate biosynthetic pathway have been identified in Arabidopsis. In Brassicaceae vegetables, mainly using syntenic information with the model plant Arabidopsis, attempts to study genetic system controlling glucosinolate biosynthesis have been made.

In B. oleracea, a gene for BoGSL-ELONG and BoGSL$P R O$ has been cloned based on Arabidopsis sequence infor- mation (Fig. 5) (Gao et al. 2005, Li and Quiros 2002, Li et al. 2003). In addition, BoGSL-ALK was cloned using a positional cloning approach in B. oleracea ( $\mathrm{Li}$ and Quiros 2003). BoGSL-ELONG, a side chain elongation gene leading to $4 \mathrm{C}$ glucosinolates, and BoGSL-PRO control propyl glucosinolate biosynthesis of $3 \mathrm{C}$. These two genes segregate independently of each other. BoGSL-ALK gene is involved in the desaturation of glucosinolate side chain. Moreover, the presence of genes for BoGSL-OXID loci and $B o G S L-O H$ loci has been inferred from the inspection of glucosinolate profiles (Giamoustaris and Mithen 1996, Mithen et al. 1995). These genes are involved in the oxidation of glucosinolate side chain and hydroxylation. Genes for BoGSL-ELONG, BoGSL-PRO, and BoGSL-ALK were mapped on a high-density $B$. oleracea linkage map together with sequences of $B o G S L-O H$. Moreover, a linkage between BoGSL-ALK, and BoGSL-OH were reported (Gao et al. 2007). Comparative genomic analysis revealed potential

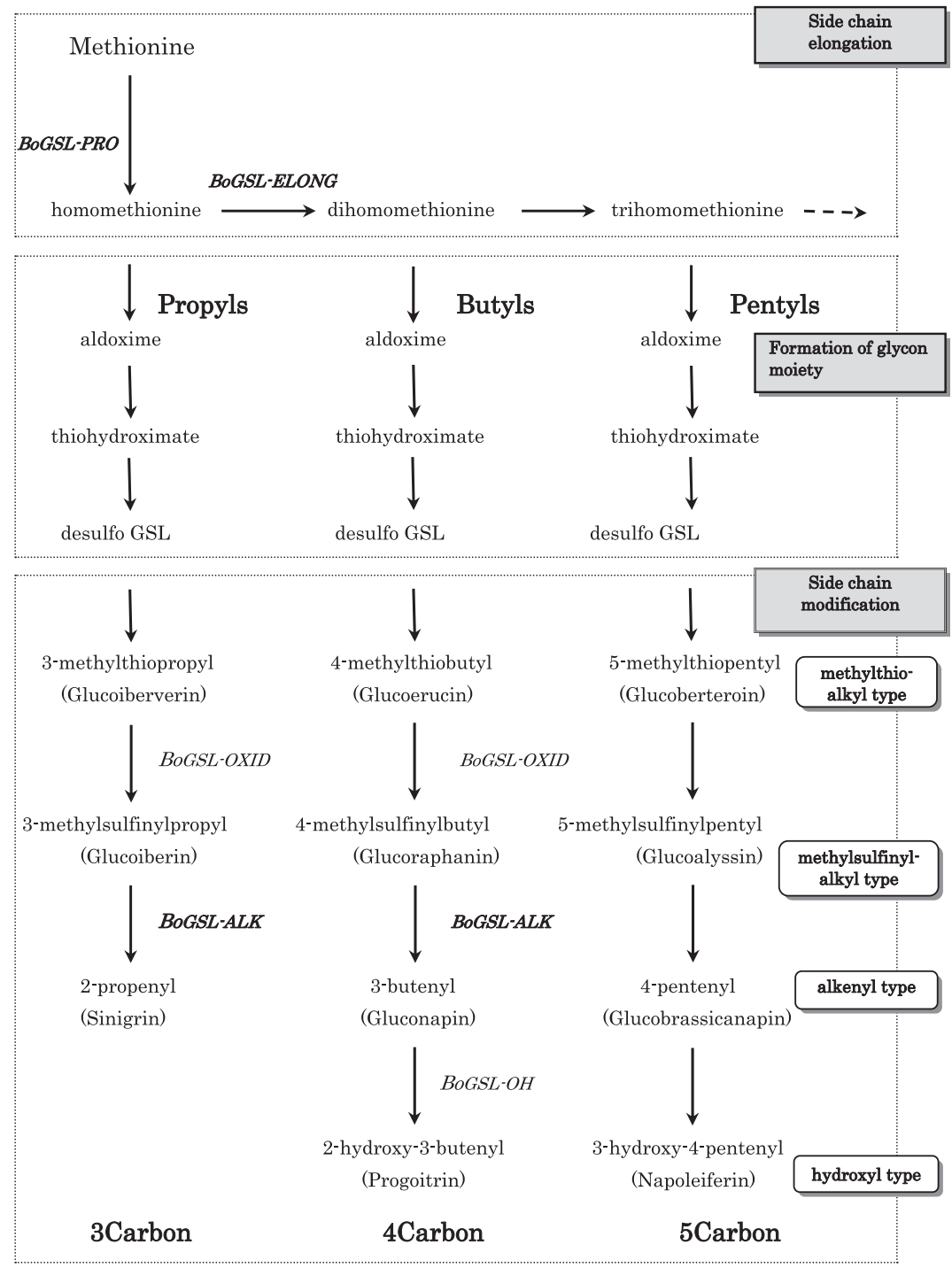

Fig. 5. Glucosinolate biosynthesis pathway for $3 \mathrm{C}, 4 \mathrm{C}$ and $5 \mathrm{C}$ aliphatic glucosinolates of Brassica. Genes set in bold have been cloned. Others have been inferred from inspection of glucosinolate profiles in B. oleracea. 
candidate genes within the regions of the quantitative trait locus (QTL) affecting glucosinolate biosynthesis (Issa 2010). Furthermore, in high-glucoraphanin broccoli, which was developed via marker-assisted selection through interspecific cross with a wild species of $B$. oleracea, $B$. villosa (Mithen et al. 2003), enhanced glucoraphanin content is regarded as attributable to a B. villosa Myb28 allele. Myb28 is a transcription factor gene. Its increased expression was confirmed in high-glucoraphanin broccoli (Traka et al. 2013).

In B. rapa, QTLs for leaf and seed glucosinolates were identified. The genes involved in the glucosinolate biosynthesis pathway that might account for the QTL were inferred from comparative genomic analyses based on synteny with Arabidopsis and mapping of candidate orthologous genes in B. rapa (Hirani 2011, Lou et al. 2008). Chinese cabbage lines with altered glucosinolate profiles were achieved through a cross between $B$. rapa and B. oleracea using marker-assisted selection (Hirani 2011). Recently, glucosinolate biosynthetic genes were identified from cDNA/BAC libraries and whole genome sequence of $B$. rapa. High collinearity in the glucosinolate biosynthetic pathway between $A$. thaliana and $B$. rapa has been established using comparative genomic analysis (Wang et al. 2011, Zang et al. 2009). Based on the DNA sequences from Arabidopsis and B. oleracea for genes involved in glucosinolate biosynthesis, candidate genes were co-mapped with glucosinolate QTLs reported by Ramchiary et al. (2007). The functionality and contribution of candidate genes/QTLs were assessed.

For amphidiploid crop B. napus, several QTL mapping studies of seed glucosinolate content (Quijada et al. 2006, Toroser et al. 1995, Uzunova et al. 1995, Zhao and Meng 2003), and gene-linked SSR markers have been used to ascertain the relation of functionally characterized Arabidopsis genes to seed glucosinolate content of B. napus (Hasan et al. 2008). Recently, a glucosinolate metabolic network was constructed. Functions of genes that underlie QTLs in it were inferred (Feng et al. 2012). In another amphidiploid crop B. juncea, QTLs (Lionneton et al. 2004, Mahmood et al. 2003) and SCAR markers (Ripley and Roslinsky 2005) have been reported for seed glucosinolate contents.

For a crop other than Brassica, R. sativus, QTL analyses using high-density mapping and identification of candidate genes controlling glucosinolate content in roots have been reported (Zou et al. 2013). Five QTLs were detected in two $\mathrm{F}_{2}$ populations, with three of them accounting for more than $50 \%$ of the total phenotypic variance being detected repeatedly. By synteny analysis of the QTL regions with $A$. thaliana and B. rapa genome sequences, three candidate genes were indicated. Their possible function in dehydroerucin biosynthesis in radish roots was suggested by nucleotide sequences and expression of these genes.

\section{Present and future of glucosinolate breeding}

The main breeding objectives for Brassicaceae vegetables are the enhancement of beneficial glucosinolates such as glucoraphanin for anticarcinogenic compounds in broccoli or dehydroerucin for pungent condiments in radish, and the reduction of precursor glucosinolate of antinutritional compounds, such as progoitrin in B. oleracea, which includes cabbage.

In $B$. oleracea, a gene has been cloned for $B o G S L$ ELONG, BoGSL-PRO and BoGSL-ALK, which control the metabolism of aliphatic glucosinolate. The inheritance of these genes is simple. Li and Quiros (2002) were elucidating the phenotype BoGSL-ELONG/BoGSL-PRO/BoGSL$A L K$ of broccoli, cauliflower and purple cauliflower, and provided a historic scenario for the origin of purple cauliflower. Elucidation of the inheritance of major genes controlling glucosinolate biosynthesis is necessary not only to clarify the genetic relation, but also to develop a new cultivar with specific glucosinolate profiles. Even among them, DNA marker for both Mendelian genes and major QTLs would be useful for glucosinolate breeding programs.

The best known example is, as described above, the development of super broccoli. Much more than standard broccoli cultivars, it contains higher levels of methylsulphinylalkyl glucosinolate (glucoiberin and glucoraphanin), the precursors of the functionality isothiocyanates iberin and sulforaphane. The wild forms of B. oleracea, B. villosa, which accumulate high levels of glucoiberin in flower buds, were used as a parent in this program. The hybrid lines, which had a high level of methylsulphinylalkyl glucosinolate, were selected using DNA markers linked to BoGSLELONG gene. These high glucosinolate broccolis had shown higher functionality than that shown by standard cultivars (Gasper et al. 2005). These might be suitable for increasing the amount of functional isothiocyanates in human food.

In radish, which is an important vegetable in Japan, a novel mutant that lacked dehydroerucin was identified (Ishida et al. 2012b). This mutant plant was discovered from a Japanese local variety through an intensive evaluation of glucosinolate profiles in many genetic resources using HPLC analyses. From the null mutants of dehydroerucin, a new cultivar, 'Daikon Chukanbohon Nou 5' ('Daikon parental line 5'), was bred in 2012. This cultivar is characterized by its abundance of glucoerucin compared with common cultivars. This characteristic is stable throughout the growing period. When used with this cultivar for making Japanese pickled radish (takuan), no yellow color and sulfurous odor is generated. Using this cultivar as a breeding material is expected to engender the development of new cultivars providing excellent agronomic performance for the production of novel processed foods.

The most commonly consumed vegetable in eastern Asia is B. rapa. Its glucosinolate profiles differ from those of $B$. oleracea. However, the breeding for altering glucosinolate profiles does not progress because its study has been delayed compared with that of B. oleracea. In the near future, development of molecular markers using sequenced genome information will promote marker-assisted selection 
of glucosinolates breeding to increase beneficial glucosinolates such as glucoraphanin in Brassicaceae vegetables including B. rapa.

Certain glucosinolates such as sinigrin and progoitrin, and their respective breakdown products are often bitter or astringent (Drewnowski and Gomez-Carneros 2000). Humans often reject foods that taste excessively bitter. This instinctive rejection is believed to have been important for human safety because it can protect people from consuming some potential toxins. The removal of specific glucosinolates and their breakdown products is thought to reduce bitterness and to increase consumer acceptance. Consumer reports have described that taste, rather than recognized nutrition or health value, is the key to food selection (Schonhof et al. 2004). For this reason, expectations of consumer willingness to compromise on the taste of glucosinolateenriched vegetables for health value are risky. Moreover, those efforts might only appeal to a niche market (Williams and Pun 2011). Improvement of glucosinolate compounds for human health or processing fitness requires not only the pursuit of breeding efficiency by marker-assisted selection or new analytical methods but also careful consideration of the taste of Brassicaceae vegetables.

\section{Acknowledgments}

This work was supported by a grant from the Ministry of Agriculture, Forestry and Fisheries of Japan (Genomicsbased Technology for Agricultural Improvement, HOR1006).

\section{Literature Cited}

Agrawal,A.A. and N.S. Kurashige (2003) A role for isothiocyanates in plant resistance against the specialist herbivore Pieris rapae. J. Chem. Ecol. 29: 1403-1415.

Bjerg, B. and H. Sørensen (1987) Quantitative analysis of glucosinolates and HPLC of intact glucosinolates. In: Wathelet, J.-P. (ed.) Glucosinolates in rapeseeds: Analytical aspects, Martinus Nijhoff Publishers, Dordrecht. Netherlands, pp. 125-150.

Bjorkqvist, B. and A. Hase (1988) Separation and determination of intact glucosinolates in rapeseed by high-performance liquid chromatography. J. Chromatogr. 435: 501-507.

Bones,A.M. and J.T.Rossiter (1996) The myrosinase-glucosinolate system, its organisation and biochemistry. Physiol. Plantarum 97: 194-208.

Bones,A.M. and J.T. Rossiter (2006) The enzymic and chemically induced decomposition of glucosinolates. Phytochemistry 67: 10531067.

Brader, G., E. Tas and E.T.Palva (2001) Jasmonate-dependent induction of indole glucosinolates in Arabidopsis by culture filtrates of the nonspecific pathogen Erwinia carotovora. Plant Physiol. 126: $849-860$

Carlson, D.G., M.E. Daxenbichler and C.H.Van Etten (1985) Glucosinolate in radish cultivars. J. Amer. Soc. Hort. Sci. 110: 634-638.

Carlson, D.G., M.E. Daxenbichler and C.H. Van Etten (1987) Glucosinolates in crucifer vegetables: broccoli, brussels sprouts, cauliflower, collards, kale, mustard greens, and kohlrabi. J. Amer. Soc.
Hort. Sci. 112: 173-178.

Cartea, M.E. and P. Velasco (2008) Glucosinolates in Brassica foods: Bioavailability in food and significance for human health. Phytochem. Rev. 7: 213-229.

Charron, C.S. and C.E. Sams (2004) Glucosinolate content and myrosinase activity in rapid-cycling Brassica oleracea grown in a controlled environment. J. Amer. Soc. Hort. Sci. 129: 321-330.

Chen, X.J., Z.J.Zhu, X.L. Ni and Q.Q. Qian (2006) Effect of nitrogen and sulfur supply on glucosinolates in Brassica campestris spp. chinensis. Agric. Sci. China 5: 603-608.

Clarke,D.B. (2010) Glucosinolate, structures and analysis in food. Anal. Methods 2: 310-325.

Dinkova,A.T., W.D.Holtzciaw，R.N.Cole，K.Itoh， N. Wakabayashi, Y. Katoh, M. Yamamoto and P. Talalay (2002) Direct evidence that sulfhydryl groups of Keap1 are the sensors regulating induction of phase 2 enzymes that protect against carcinogens and oxidants. Proc. Natl. Acad. Sci. USA 99: 11908-11913.

Drewnowski,A. and C. Gomez-Carneros (2000) Bitter taste, phytonutrients, and the consumer: a review. Am. J. Clin. Nutr. 72: 14241435.

Fahey, J.W., A.T. Zalcmann and P. Talalay (2001) The chemical diversity and distribution of glucosinolates and isothiocyanates among plants. Phytochemistry 56: 5-51.

Fahey, J.W., K.K. Stephenson, K.L. Wade and P. Talalay (2013) Urease from Helicobacter pylori is inactivated by sulforaphane and other isothioyanates. Biochem. Biophys. Res. Commun. 435: 1-7.

Feng, J., Y.Long, L. Shi, J. Shi, G. Barker and J. Meng (2012) Characterization of metabolite quantitative trait loci and metabolic networks that control glucosinolate concentration in the seeds and leaves of Brassica napus. New Phytol. 193: 96-108.

Fenwick, G.R., R.K. Heaney and W.J. Mullin (1983) Glucosinolate and their breakdown products in food and plants. Crit. Rev. Food Sci. Nutr. 18: 123-201.

Foo, H.L., ～L.M. Gronning, L. Goodenough, A.M.Bones, B.E. Danielsen, D.A. Whiting and J.T.Rossiter (2000) Purification and characterisation of epithiospecifier protein from Brassica napus: enzymic intramolecular sulphur addition within alkenyl thiohydroximates derived from alkenyl glucosinolate hydrolysis. FEBS Lett. 468: 243-246.

Gamet-Payrastre,L., P.Li, S.Lumeau, G.Cassar, M-A.Dupont, S. Chevolleau, N. Gasc, J. Tulliez and F. Tercé (2000) Sulforaphane, a naturally occurring isothiocyanate, induces cell cycle arrest and apoptosis in HT29 human colon cancer cells. Cancer Res. 60: 1426-1433.

Gao,M., G.Li, W.McCombie and C.Quiros (2005) Comparative analysis of a transposon-rich Brassica oleracea BAC clone with its corresponding sequence in A. thaliana. Theor. Appl. Genet. 111: 949-955.

Gao, M., G.Li, B.Yang, D. Qiu, M.Farnham and C.Quiros (2007) High-density Brassica oleracea linkage map: identification of useful new linkages. Theor. Appl. Genet. 115: 277-287.

Gasper,A.V., A.Al-Janobi, J.A. Smith, J.R.Bacon, P.Fortun, C. Atherton, M.A. Taylor, C.J.Hawkey, D.A. Barrett and R.F. Mithen (2005) Glutathione S-transferase M1 polymorphism and metabolism of sulforaphane from standard and high-glucosinolate broccoli. Am. J. Clin. Nutr. 82: 1283-1291.

Giamoustaris, A. and R. Mithen (1996) Genetics of aliphatic glucosinolates. IV. Side-chain modification in Brassica oleracea. Theor. Appl. Genet. 93: 1006-1010.

Griffiths, D.W., A.N.E. Birch and J.R.Hillman (1998) Antinutritional compounds in the Brassicaceae: Analysis, biosynthesis, chemistry 
and dietary effects. J. Hort. Sci. Biotech. 73: 1-18.

Grubb,C.D. and S.Abel (2006) Glucosinolate metabolism and its control. Trends Plant Sci. 11: 89-100.

Halkier, B.A. and J.Gershenzon (2006) Biology and biochemistry of glucosinolates. Ann. Rev. Plant Biol. 57: 303-333.

Hara, M., Y. Fujii, Y. Sasada and T. Kuboi (2000) cDNA cloning of radish (Raphanus sativus) myrosinase and tissue-specific expression in root. Plant Cell Physiol. 41: 1102-1109.

Hara, M., H.Eto and T.Kuboi (2001) Tissue printing for myrosinase activity in roots of turnip and Japanese radish and horseradish: a technique for localizing myrosinases. Plant Sci. 160: 425-431.

Hara, M., A. Harazaki and K. Tabata (2013) Administration of isothiocyanates enhances heat tolerance in Arabidopsis thaliana. Plant Growth Regul. 69: 71-77.

Hasan, M., W. Friedt, J.Pons-Kuhnemann, N.M.Freitag, K. Link and R.J. Snowdon (2008) Association of gene-linked SSR markers to seed glucosinolate content in oilseed rape (Brassica napus spp. napus). Theor. Appl. Genet. 116: 1035-1049.

Herr, I. and M.W. Büchler (2010) Dietary constituents of broccoli and other cruciferous vegetables: Implications for prevention and therapy of cancer. Cancer Treat. Rev. 36: 377-383.

Hirani,A.H. (2011) QTL mapping, gene identification and genetic manipulation of glucosinolates in Brassica rapa L. Ph.D. Thesis, University of Manitoba, Canada.

Hirani,A.H., G. Li, C.D.Zelmer, P.B.E. McVetty, M.Asif and A. Goyal (2012) Molecular genetics of glucosinolate biosynthesis in Brassicas: Genetic manipulation and application aspects. In: Goyal,A. (ed.) Crop Plant. DOI: 10.5772/45646. Available from: http://www.intechopen.com/books/crop-plant/molecular-geneticsof-glucosinolate-biosynthesis-in-brassicas

Hopkins, R.J., N.M.van Dam and J.J.van Loon (2009) Role of glucosinolates in insect-plant relationships and multitrophic interactions. Annu. Rev. Entomol. 54: 57-83.

Husebye, H., S. Chadchawan, P. Winge, O.P. Thangstad and A.M. Bones (2002) Guard cell- and phloem idioblast-specific expression of thioglucoside glucohydrolase 1 (myrosinase) in Arabidopsis. Plant Physiol. 128: 1180-1188.

Ishida, M., T.Kakizaki, T. Ohara and Y.Morimitsu (2011) Development of a simple and rapid extraction method of glucosinolates from radish roots. Breed. Sci. 61: 208-211.

Ishida, M., M.Nagata, T.Ohara, T.Kakizaki, K. Hatakeyama and T. Nishio (2012a) Small variation of glucosinolate composition in Japanese cultivars of radish (Raphanus sativus L.) requires simple quantitative analysis for breeding of glucosinolate component. Breed. Sci. 62: 63-70.

Ishida, M., T.Kakizaki, T. Ohara and Y.Morimitsu (2012b) Raphanus breeding for glucosinolate component. Proceeding of International Symposium Comparative Genomics and Breeding of Brassica Crops. 6.

Ishii, G., R. Saijo and M. Nagata (1989) The difference of glucosinolate content in different cultivar of daikon roots (Raphanus sativus L.). Nippon Shokuhin Kogyo Gakkaishi 36: 739-742.

Issa, R.A. (2010) Identification of glucosinolate profile in Brassica oleracea for quantitative trait locus mapping. Ph.D. Thesis, University of Warwick, England.

Kelly, P.J., A. Bones and J.T. Rossiter (1998) Sub-cellular immunolocalization of the glucosinolate sinigrin in seedlings of Brassica juncea. Planta 206: 370-377.

Kiddle, G., R.N.Bennett, N.P.Botting, N.E.Davidson, A.A.B. Robertson and R.M. Wallsgrove (2001) High-performance liquid chromatographic separation of natural and synthetic desulpho- glucosinolates and their chemical validation by UV, NMR and chemical ionisation-MS methods. Phytochem. Anal. 12: 226-242.

Kim, S.J., T. Matsuo, M. Watanabe and Y.Watanabe (2002) Effect of nitrogen and sulphur application on the glucosinolate content in vegetable turnip rape (Brassica rapa L.). Soil Sci. Plant Nutr. 48: 43-49.

Kim, S.J. and G. Ishii (2007) Effect of storage temperature and duration on glucosinolate, total vitamin $\mathrm{C}$ and nitrate contents in rocket salad (Eruca sativa Mill.). J. Sci. Food Agric. 87: 966-973.

Kirkegaard, J.A. and M. Sarwar (1998) Biofumigation potential of brassicas I. Variation in glucosinolate profiles of diverse fieldgrown brassicas. Plant Soil 201: 71-89.

Kissen, R., J.T. Rossiter and A.M.Bones (2009) The 'mustard oil bomb': not so easy to assemble?! Localization, expression and distribution of the components of the myrosinase enzyme system. Phytochem. Rev. 8: 69-86.

Kojima, M. and K. Ogawa (1971) Studies of the effects of isothiocyanates and their analogues on microorganisms, (1) Effects of isothiocyanates on the oxygen uptake of yeasts. J. Ferment. Technol. 49: 740-746.

Koroleva, O.A., A. Davies, R.Deeken, M.R.Thorpe, A.D. Tomos and R. Hedrich (2000) Identification of a new glucosinolate-rich cell type in Arabidopsis flower stalk. Plant Physiol. 124: 599-608.

Kostova,A.T.D., J.W. Fahey, K.L.Wade, S.N. Jenkins, T.A. Shapiro, E.J.Fuchs, M.L.Kerns and P.Talalay (2007) Induction of phase 2 response in mouse and human skin by sulforaphane-containing broccoli sprout extracts. Cancer Epidemiol. Biomarkers Prev. 16: 847-851.

LeCoz, C.J. and G.Ducombs (2006) Plants and plant products. In: Frosch, P.J., T. Menne and J.P. Lepottevin (eds.) Contact Dermatitis, 4th ed., Springer Verlag, Berlin-Heidelberg, Germany, pp. 751800 .

Li, G. and C.F. Quiros (2002) Genetic analysis, expression and molecular characterization of BoGSL-ELONG, a major gene involved in the aliphatic glucosinolate pathway of Brassica species. Genetics 162: 1937-1943.

Li, G., M. Gao, B. Yang and C.F. Quiros (2003) Gene to gene alignment between the Brassica and Arabidopsis genomes by transcriptional mapping. Theor. Appl. Genet. 107: 168-180.

Li, G. and C.F. Quiros (2003) In planta side-chain glucosinolate modification in Arabidopsis by introduction of dioxygenase Brassica homolog BoGSL-ALK. Theor. Appl. Genet. 106: 1116-1121.

Lionneton, E., G. Aubert, S. Ochatt and O. Merah (2004) Genetic analysis of agronomic and quality traits in mustard (Brassica juncea). Theor. Appl. Genet. 109: 792-799.

Lou, P., J.Zhao, H.He, C.Hanhart, D. Del Carpio, R. Verkerk, J. Custers, M. Koornneef and G. Bonnema (2008) Quantitative trait loci for glucosinolate accumulation in Brassica rapa leaves. New Phytol. 179: 1017-1032.

Ludwig-Müller, J., P. Krishna and C. Forreiter (2000) A glucosinolate mutant of Arabidopsis is thermosensitive and defective in cytosolic Hsp90 expression after heat stress. Plant Physiol. 123: 949-958.

Mahmood,T., U.Ekuere, F.Yeh, A.Good and G.Stringam (2003) Molecular mapping of seed aliphatic glucosinolates in Brassica juncea. Genome 46: 753-760.

Manici, L.M., L. Lazzeri and S. Palmieri (1997) In vitro fungitoxic activity of some glucosinolates and their enzyme-derived products toward plant pathogenic fungi. J. Agric. Food Chem. 45: 27682773.

Mellon, F.A., R.N. Bennett, B. Holst and G. Willia (2002) Intact glucosinolate analysis in plant extracts by programmed cone voltage 
electrospray LC/MS: Performance and comparison with LC/MS/ MS methods. Anal. Biochem. 306: 83-91.

Miao, H., J. Wei, Y.Zhao, H. Yan, B. Sun, J.Huang and Q. Wang (2013) Glucose signalling positively regulates aliphatic glucosinolate biosynthesis. J Exp. Bot. 64: 1097-1109.

Mithen, R.F., J. Clarke, C. Lister and C.Dean (1995) Genetics of aliphatic glucosinolates. III. Side chain structure of aliphatic glucosinolates in Arabidopsis thaliana. Heredity 74: 210-215.

Mithen, R.F., M. Dekker, R. Verkerk, S. Rabot and L.T. Johnson (2000) The nutritional significance, biosynthesis and bioavailability of glucosinolates in human foods. J. Sci. Food Agric. 80: 967-984.

Mithen, R., K. Faulkner, R. Magrath, P. Rose, G.Williamson and J. Marquez (2003) Development of isothiocyanate-enriched broccoli, and its enhanced ability to induce phase 2 detoxification enzymes in mammalian cells. Theor. Appl. Genet. 106: 727-734.

Morimitsu,Y., K.Hayashi, Y.Nakagawa, F.Horio, K.Uchida and T. Osawa (2000) Antiplatelet and anticancer isothiocyanates in Japanese domestic horseradish, wasabi. BioFactors 13: 271-276.

Morimitsu,Y., Y.Nakagawa, K. Hayashi, H.Fujii, T.Kumagai, Y. Nakamura, T. Osawa, F.Horio, K.Itoh, K.Iida et al. (2002) A sulforaphane analog that potently activates the Nrf2-dependent detoxification pathway. J. Biol. Chem. 277: 3456-3463.

Munday, R., P. Mhawech-Fauceglia, C.M. Munday, J.D. Paonessa, L. Tang, J.S. Munday, C. Lister, P. Wilson, J.W. Fahey, W. Davis et al. (2008) Inhibition of urinary bladder carcinogenesis by broccoli sprouts. Cancer Res. 68: 1593-1600.

Ozawa, Y., Y.Uda, T. Ohshima, K. Saito and Y.Maeda (1990) Formation of yellow pigment by the reaction of 4-methylthio-3-butenyl isothiocyanate with L-ascorbic acid and some dihydroxyphenolic compounds. Agric. Biol. Chem. 54: 605-611.

Padilla, G., M.E. Cartea, P. Velasco, A. Haro and A. Ordás (2007) Variation of glucosinolates in vegetable crops of Brassica rapa. Phytochemistry 68: 536-545.

Parnaud, G., P.Li, G.Cassar, P. Rouimi, J.Tulliez, L.Combaret and L. Gamet-Payrastre (2004) Mechanism of sulforaphane-induced cell cycle arrest and apoptosis in human colon cancer cells. Nutr. Cancer 48: 198-206.

Pereira, F.M., E. Rosa, J.W.Fahey, K.K. Stephenson, R. Carvalho and A.Aires (2002) Influence of temperature and ontogeny on the levels of glucosinolates in broccoli (Brassica oleracea var. italica) sprouts and their effect on the induction of mammalian phase 2 enzymes. J Agric. Food Chem. 50: 6239-6244.

Piero, A.R.L., I. Puglisi and G. Petrone (2006) Gene isolation, analysis of expression, and in vitro synthesis of glutathione $S$-transferase from orange fruit [Citrus sinensis L. (Osbeck)]. J. Agric. Food Chem. 54: 9227-9233.

Quijada, P.A., J.A.Udall, B. Lambert and T.C.Osborn (2006) Quantitative trait analysis of seed yield and other complex traits in hybrid spring rapeseed (Brassica napus L.): 1. Identification of genomic regions from winter germplasm. Theor. Appl. Genet. 113: 549-561.

Ramchiary, N., N.C. Bisht, V. Gupta, A. Mukhopadhyay, N. Arumugam, Y.S. Sodhi, D.Pental and A.K.Pradhan (2007) QTL analysis reveals context-dependent loci for seed glucosinolate trait in the oilseed Brassica juncea: importance of recurrent selection backcross scheme for the identification of 'true' QTL. Theor. Appl. Genet. 116: $77-85$.

Rangkadilok, N., M.E.Nicolas, R.N.Bennett, R.R.Premier, D.R. Eagling and P.W.J. Taylor (2002) Developmental changes of sinigrin and glucoraphenin in three Brassica species (Brassica nigra, Brassica juncea and Brassica oleracea var. Italica). Sci. Hortic. 96: $11-26$.
Rask, L., E.Andreasson, B.Ekbom, S.Eriksson, B.Pontoppidan and J. Meijer (2000) Myrosinase: gene family evolution and herbivore defense in Brassicaceae. Plant Mol. Biol. 42: 93-113.

Ripley, V.L. and V. Roslinsky (2005) Identification of an ISSR marker for 2-propenyl glucosinolate content in Brassica juncea L. and conversion to a SCAR marker. Mol. Breed. 16: 57-66.

Rosa,E.A.S., R.K.Heaney, G.R.Fenwick and C.A.M.Portas (1997) Glucosinolates in crop plants. Hortic. Rev. 19: 99-125.

Sang, J.P., I.R. Minchinton, P.K. Johnstone and R.J.W. Truscott (1984) Glucosinolate profiles in the seed, root and leaf tissue of cabbage, mustard, rapeseed, radish and swede. Can. J. Plant Sci. 64: 77-93.

Schonhof,I., A. Krumbein and B. Brückner (2004) Genotypic effects on glucosinolates and sensory properties of broccoli and cauliflower. Nahrung 48: 25-33.

Sønderby, I.E., M.Burow, H.C.Rowe, D.J.Kliebenstein and B.A. Halkier (2010a) Complex interplay of three $R_{2} R_{3}$ MYB transcription factors determines the profile of aliphatic glucosinolates in Arabidopsis. Plant Physiol. 153: 348-363.

Sønderby, I.E., F. Geu-Flores and B.A. Halkier (2010b) Biosynthesis of glucosinolates - gene discovery and beyond. Trends Plant Sci. 15: 283-290.

Stoewsand, G.S. (1995) Bioactive organosulfur phytochemicals in Brassica oleracea vegetables-A review. Food Chem. Toxicol. 33: 537-543.

The International Organization for Standardization (1992) RapeseedDetermination of glucosinolate content. ISO. 9167-1: 1992(2). $1-9$.

Thies, W. (1982) Complex-formation between glucosinolates and tetrachloropalladate (II) and its utilization in plant breeding. Fette. Seifen. Anstrichm. 84: 338-342.

Tierens, K.F., B.P.Thomma, M. Brouwer, J.Schmidt, K. Kistner, A. Porzel, B. Mauch-Mani, B.P.Cammue and W.F. Broekaert (2001) Study of the role of antimicrobial glucosinolate-derived isothiocyanates in resistance of Arabidopsis to microbial pathogens. Plant Physiol. 125: 1688-1699.

Toroser, D., C.Thormann, T. Osborn and R. Mithen (1995) RFLP mapping of quantitative trait loci controlling seed aliphaticglucosinolate content in oilseed rape (Brassica napus L). Theor. Appl. Genet. 91: 802-808.

Traka, M. and R. Mithen (2009) Glucosinolates, isothiocyanates and human health. Phytochem. Rev. 8: 269-282.

Traka,M., S.Saha, S.Huseby, S.Kopriva, P.Walley, G. Barker, J. Moore, G. Mero, F. van den Bosch, H. Constant et al. (2013) Genetic regulation of glucoraphanin accumulation in Beneforte broccoli. New Phytol. 198: 1085-1095.

Tripathi, M.K. and A.S. Mishra (2007) Glucosinolates in animal nutrition: A review. Anim. Feed Sci. Tech. 132: 1-27.

Uda, Y., H. Matsuoka, H. Kumagami, H. Shima and Y. Maeda (1993) Stability and antimicrobial property of 4-methylthio-3-butenyl isothiocyanate, the pungent principle in radish. Nippon Shokuhin Kogyo Gakkaishi 40: 743-746.

Uzunova, M., W.Ecke, K. Weissleder and G. Röbbelen (1995) Mapping the genome of rapeseed (Brassica napus L.). I. Construction of an RFLP linkage map and localization of QTLs for seed glucosinolate content. Theor. Appl. Genet. 90: 194-204.

van Lieshout, E.M., G.H. Posner, B.T. Woodard and W.H. Peters (1998) Effects of sulforaphane analog compound 30, indole-3-carbinol, D-limonene or relafen on glutathione $S$-transferases and glutathione peroxidase of the rat digestive tract. Biochem. Biophys. Acta 1379: 325-336.

Verkerk, R., M. Schreiner, A. Krumbein, E. Ciska, B. Holst, I. Rowland, 
R.D. Schrijver, M.Hansen, C. Gerhäuser, R. Mithen et al. (2009) Glucosinolates in Brassica vegetables: The influence of the food supply chain on intake, bioavailability and human health. Mol. Nutr. Food Res. 53: S219-S265.

Wang, X., H.Wang, J.Wang, R. Sun, J.Wu, S.Liu, Y.Bai, J.H.Mun, I. Bancroft, F. Cheng et al. (2011) The genome of the mesopolyploid crop species Brassica rapa. Nat. Genet. 43: 1035-1039.

Watai, Y., A.Kobayashi, H.Nagase, M.Mizukami, J.McEvoy, J.D. Singer, K. Itoh and M. Yamamoto (2007) Subcellular localization and cytoplasmic complex status of endogenous Keap1. Genes Cells 12: 1163-1178.

Whitty, J.P. and L.F.Bjeldanes (1987) The effects of dietary cabbage on xenobiotic-metabolizing enzymes and the binding of aflatoxin $\mathrm{B}_{1}$ to hepatic DNA in rats. Food Chem. Toxicol. 25: 581-587.

Wiesner, M., R.Zrenner, A.Krumbein, H. Glatt and M.Schreiner (2013) Genotypic variation of the glucosinolate profile in pak choi (Brassica rapa spp. chinensis). J. Agric. Food Chem. 61: 19431953.

Williams, D.J. and S.Pun (2011) Glucosinolates in Brassica vegetables: role in bitterness and hence significance. Food Australia 63: 407-412.

Wu, C.C., L.Y.Sheen, H.W.Chen, W.W.Kuo, S.J.Tsai and C.K.Lii (2002) Differential effects of garlic oil and its three major organosulfur components on the hepatic detoxification system in rats. J. Agric. Food Chem. 50: 378-383.
Yang, B. and C.F. Quiros (2010) Survey of glucosinolate variation in leaves of Brassica rapa crops. Genet. Resour. Crop Evol. 57: 1079-1089.

Zhang, Y., P. Talalay, C.-G. Cho and G.H. Posner (1992) A major inducer of anticarcinogenic protective enzymes from broccoli: isolation and elucidation of structure. Proc. Natl. Acad. Sci. USA 89: 23992403.

Zhang, Y., R. Munday, H.E. Jobson, C.M. Munday, C. Lister, P. Wilson, J.W. Fahey and P.M. Fauceglia (2006) Induction of GST and NQO1 in cultured bladder cells and in the urinary bladders of rats by an extract of broccoli (Brassica oleracea italica) sprouts. J. Agric. Food Chem. 54: 9370-9376.

Zang, Y.X., H.U. Kim, J.A. Kim, M.H.Lim, M. Jin, S.C. Lee, S.J. Kwon, S.I.Lee, J.K.Hong, T.H. Park et al. (2009) Genome-wide identification of glucosinolate synthesis genes in Brassica rapa. FEBS J. 276: 3559-3574.

Zhao, J. and J. Meng (2003) Detection of loci controlling seed glucosinolate content and their association with Sclerotinia resistance in Brassica napus. Plant Breed. 122: 19-23.

Zou,Z., M.Ishida, F.Li, T.Kakizaki， S. Suzuki， H.Kitashiba and T. Nishio (2013) QTL analysis using SNP markers developed by next-generation sequencing for identification of candidate genes controlling 4-methylthio-3-butenyl glucosinolate contents in roots of radish, Raphanus sativus L. PLoS One 8: e53541. 